\title{
Non-specific reactions in enzyme linked immunosorbent assays for serum antibody to Entamoeba histolytica and Giardia lamblia in non-endemic areas
}

\author{
N P Shetty, I S Raj, R S Macaden
}

\begin{abstract}
Serum samples from 20 Indian children with diarrhoea were compared with those from 20 children resident in the United Kingdom who had been diagnosed as having ulcerative colitis, or Crohn's disease, or indeterminate colitis using enzyme linked immunosorbent assays specific for Entamoeba histolytica and Giardia lamblia.

More than $50 \%$ of the United Kingdom patients had high IgG responses in ELISAs for E histolytica and G lamblia. A confirmatory ELISA showed that the British sera reacted specifically to bovine serum proteins rather than to protozoal antigens. Prior incubation of sera with $5 \%$ bovine serum prohibited this reaction. Bovine serum is an integral part of the crude soluble antigen used in most ELISAs for $E$ histolytica and $G$ lamblia and needs to be replaced with purified antigen preparations. The British sera also reacted to other commonly used blocking agents such as bovine serum albumin, casein, and normal sheep serum. These reactions were attributed to uptake of dietary antigens or an enhanced immunological response to these antigens in patients with inflammatory bowel disease.
\end{abstract}

A serum antibody test for amoebiasis is sometimes indicated to differentiate acute amoebic colitis from ulcerative colitis or Crohn's disease. ${ }^{1}$ The detection of specific anti-Giardia serum antibody is a valuable diagnostic tool, especially in non-endemic areas, to differentiate clinical giardiasis from diarrhoeas caused by a variety of other causes. $^{2}$

Several protocols exist for the measurement of serum antibody to Entamoeba histolytica and Giardia lamblia using enzyme linked immunosorbent assays (ELISAs) ${ }^{3-5}$ During a collaborative study these assays were conducted on a batch of 20 sera from children resident in the United Kingdom who had been diagnosed as having ulcerative colitis. Crohn's disease, or indeterminate colitis. This was done to compare baseline values from a non-endemic but symptomatic population with those of children with diarrhoea from an endemic area.
Methods

Serum samples from 20 Indian children (age range 0-12 years) were collected during an episode of diarrhoea and stored at $-20^{\circ} \mathrm{C}$ until tested. Twenty stored serum samples from British children were obtained from Professor J Walker-Smith, Department of Paediatric Gastroenterology, St Bartholomew's Hospital, London. These children (age range 8-15 years) had been variously diagnosed as having ulcerative colitis, Crohn's disease, or indeterminate colitis.

\section{ELISA FOR ANTIBODY TO E histolytica}

The original protocol was essentially that of Yang and Kennedy, with certain modifications. ${ }^{3}$ Polyvinyl and polycarbonate ELISA plates (Dynatech, Alexandria, Virginia, USA) were used for the assay. Antigen protein (2.5 $\mu \mathrm{g} / \mathrm{ml}$ ) from a sonicate of the National Institutes of Health 200 strain of $E$ histolytica was used after chequerboard titration to coat plates overnight at $4^{\circ} \mathrm{C}$. Carbonate bicarbonate buffer ( $\mathrm{pH} \mathrm{9.6)}$ was used as coating buffer. Reagents (100 $\mu$ l volumes) were used in all steps and incubation times were one hour at $37^{\circ} \mathrm{C}$, unless otherwise specified. All washing was done three times, with phosphate buffered saline (PBS) (pH 7.2) with $0.05 \%$ Tween 20. Plates were blocked with $2 \%$ ELISA grade bovine serum albumin (BSA, Sigma, St Louis, Missouri, USA) in PBS with $0.05 \%$ Tween 20 . Test sera were diluted 1 in 200 in PBS with $1 \%$ BSA according to the standard protocol. In subsequent ELISAs several alternative diluents were tried, such as $2 \%$ BSA in PBS; $2 \%, 5 \%$, and $10 \%$ sterile bovine serum (SBS) in PBS. Anti-IgG conjugated to horseradish peroxidase (Anti-IgGHRP, Sigma, St Louis, Missouri, USA) was used to detect specific human IgG to antigen. $3,3^{\prime}, 5,5^{\prime}$ tetra methyl benzidene (TMB) in dimethyl sulphoxide (DMSO) with hydrogen peroxide was used as substrate. ${ }^{6}$ Optical density was read at $490 \mathrm{~nm}$ using an ELISA reader (Dynatech, Alexandria, Virginia, USA) after stopping the reaction with $25 \mu$ l of $4 \mathrm{M}$ sulphuric acid. The same known human positive and negative control was used in all assays. Daily variations in colour were corrected for, using the controls as standard.

ELISA FOR ANTIBODY TO $G$ lamblia

Initial assays were done according to the method described by Goka et al. ${ }^{5}$ Thereafter 
the assays were repeated with minor modifications, and restandardised as follows. Polyvinyl and polycarbonate plates were tested as above. The original assay used whole trophozoites of axenically cultivated Portland 1 strain of $G$ lamblia in PBS to coat plates. In the modified assay $1.05 \mu \mathrm{g} / \mathrm{ml}$ of protein from a sonicate of the above strain was used after chequerboard titration. Antigen coating was done in carbonate-bicarbonate buffer ( $\mathrm{pH} \mathrm{9.6)} \mathrm{overnight} \mathrm{at}$ $4^{\circ} \mathrm{C}$. The rest of the assay was similar to that described for $E$ histolytica.

\section{Confirmatory ELISA for antibody to G lamblia}

Plates were coated with antigen as described above. All sera were diluted 1 in 200 in PBS with $1 \%$ BSA into which was added $6 \mu \mathrm{l} / \mathrm{ml}$ of the sonicated Giardia antigen $(1.05 \mu \mathrm{g}$ of protein $/ \mathrm{ml}$ ). This was done to absorb out specific anti-Giardia antibodies from the sera tested. The rest of the assay was similar to the one described above.

\section{ELISA FOR SEROLOGICAL RESPONSE TO BLOCKING AGENTS}

Three commonly used blocking agents were used as antigen to coat polycarbonate ELISA plates: $2 \%$ BSA in PBS, $2 \%$ casein in carbonate bicarbonate buffer ( $\mathrm{pH}: 9 \cdot 6$ ), and $2 \% \mathrm{vol} /$ vol normal sheep serum in PBS. All sera tested were diluted 1 in 200 in PBS with $1 \%$ BSA. The IgG response to the blocking agents was detected by anti IgG-HRP as described for the previous ELISAs. The customary blocking step with $2 \%$ BSA in PBS was omitted. Tests for reproducibility of results were done on all assays.

\section{Results}

There were no differences in the results obtained when either polyvinyl or polycarbonate plates were used. Figure 1 illustrates the reaction of the United Kingdom sera in the standard ELISA. Use of a sonicated antigen in place of the whole trophozoite antigen in the Giardia ELISA yielded identical results in that the United Kingdom sera continued to react strongly, but there was less plate to plate and

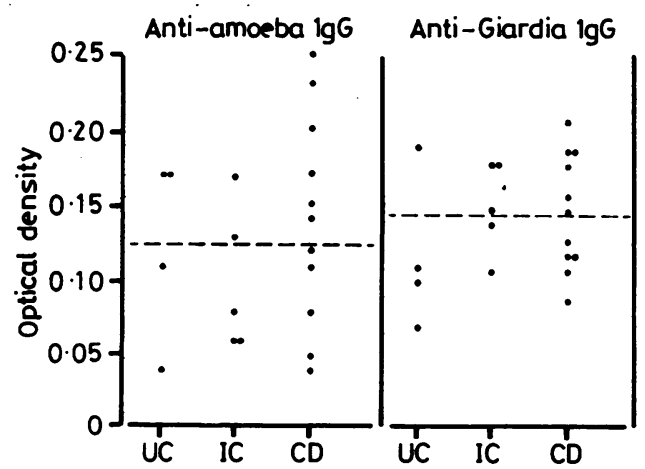

Figure 1 Amoeba/Giardia IgG ELISA done on 20 British children with inflammatory bowel disease using standard protocols. UC, ulcerative colitis; IC, indeterminate colitis; CD, Crohn's disease.

$-{ }_{-}$, median value. Median values obtained in Indian children with diarrhoea; anti-amoeba IgG 0.12 , anti-Giardia IgG 0.13.

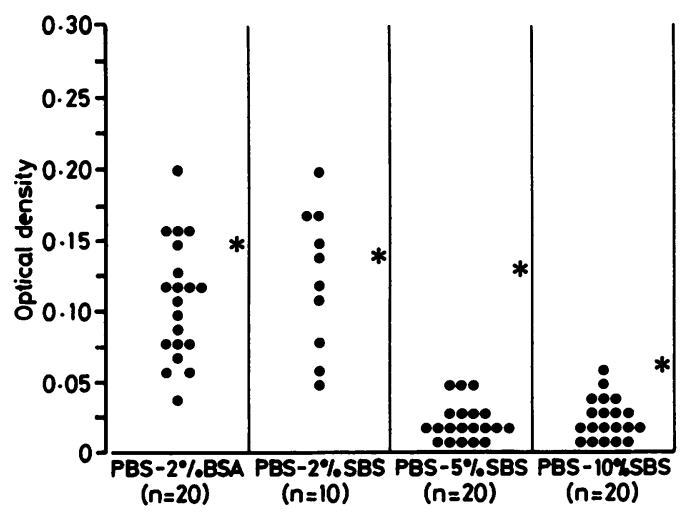

Figure 2 Giardia IgG ELISA done on British sera using various serum diluents. ${ }^{\star} K$ nown Indian positive control diluted in a similar manner.

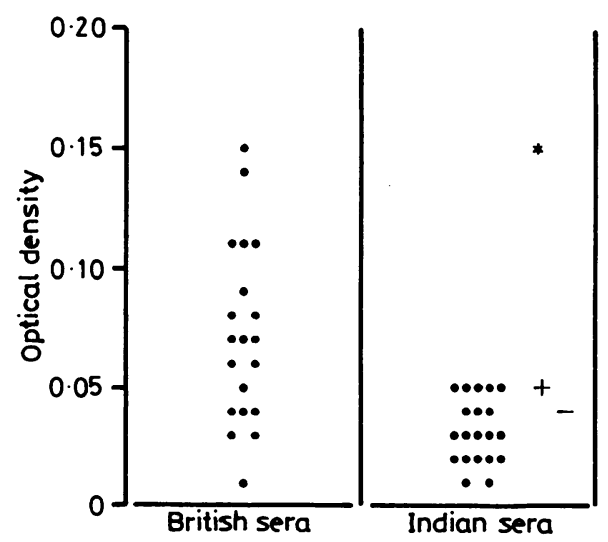

Figure 3 Confirmatory IgG ELISA for antibody to $G$ lamblia. *Indian positive control before inhibition with antigen; + Indian positive control after inhibition with antigen; - Indian negative control.

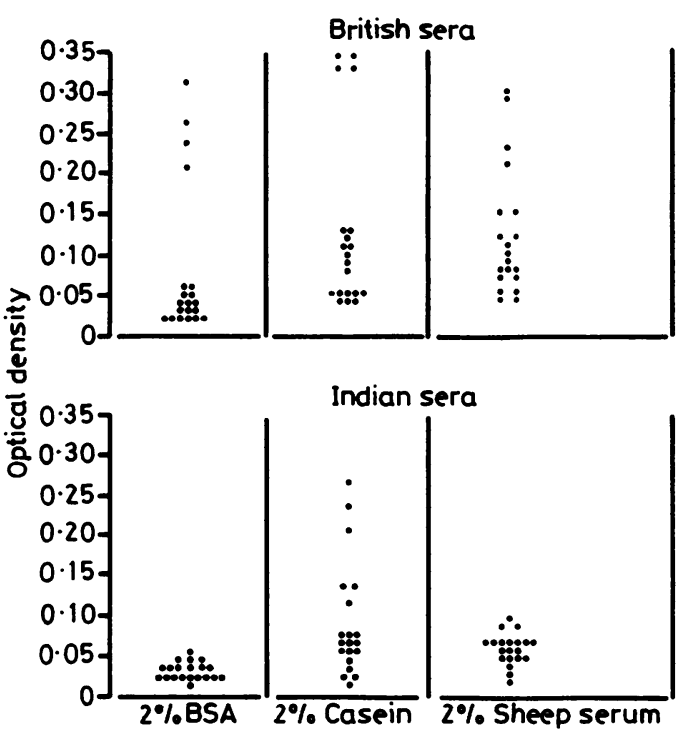

Figure 4 IgG response of British and Indian sera to various blocking agents.

day to day variation when sonicated antigen was used.

There were noticeable differences in the end result of the ELISA when the United Kingdom sera were diluted in the various diluents. Figure 2 summarises these changes, showing that a diluent containing 5\% SBS successfully eliminates the non-specific reaction. The results of the confirmatory ELISA (after sera were preincubated with test antigen) are shown in fig 3; the Indian sera reacted poorly whereas 
the United Kingdom sera continued to react positively.

The serological response of the Indian and United Kingdom children to blocking agents is shown in fig 4. This scatter diagram indicates that both ethnic groups reacted to casein, while certain United Kingdom children reacted more strongly to BSA and to sheep serum proteins than Indian children.

\section{Discussion}

An awareness of the possible non-specific reactions during ELISAs for $E$ histolytica and $G$ lamblia will enhance the diagnostic specificity of these tests in non-endemic areas. It has been widely accepted that one of the uses of these ELISAs, particularly in travellers from nonendemic areas, is to differentiate non-infective from parasitic colitis. ${ }^{12}$ Since the treatment for the former, sometimes requiring corticosteroids (as in ulcerative colitis and Crohn's disease), is contraindicated in the latter, these tests assume an even greater importance. ${ }^{1}$

In our study the cause of the non-specific reaction was initially assumed to be due to presence of antibodies to BSA, the blocking agent used in most ELISAs. The initial experiments done to ascertain reactions to several proteins commonly used as blocking agents indicated that only $25 \%$ of the United Kingdom children reacted strongly to BSA; a higher percentage reacted to casein and sheep serum. On the contrary, a significant number of Indian children produced a reaction to casein only, while their response to BSA and sheep serum proteins was low $(p<0.05)$. In their study of serum antibodies to cow's milk proteins in paediatric inflammatory bowel disease Aaron Lerner et al showed raised IgG titres to BSA in patients with Crohn's disease compared with those with ulcerative colitis or normal controls. ${ }^{7}$ Patients as well controls, however, had raised IgG titres to casein.

Several serum diluents were analysed for their ability to remove the non-specific reaction in the United Kingdom sera. The original protocol advocates the use of $1 \%$ BSA with PBS. It was found that neither $1 \%$ nor $2 \%$ BSA in PBS was useful in eliminating the nonspecific reaction. This was consistent with our earlier experiment where it was shown that only $25 \%$ of the United Kingdom children reacted to $2 \%$ BSA. A diluent with $5 \%$ and $10 \%$ SBS successfully removed the nonspecific reaction, showing that the United Kingdom sera were in fact reacting to one or more of the bovine serum proteins. The $5 \%$ serum diluent was optimal because it did not affect the value of the known Indian positive control sera diluted in the same manner. Finally, to ensure the specificity of the Giardia ELISA, a confirmatory test was done. This showed that the Indian sera had demonstrable antibodies to Giardia antigen by reacting negatively in the confirmatory ELISA. The United Kingdom sera continued to react as before in the confirmatory test, confirming the non-specific nature of the reaction. Our view is supported by a study reported by Moody et al in $1982 .{ }^{2}$ Using a cyst antigen and an immunofluorescence test, these workers showed a consistent absence of Giardia antibody from the serum of patients with ulcerative colitis and Crohn's disease.

It is still not clear whether the nonspecificity occurs because bovine serum may form an integral part of either type of antigen (whole trophozoite and sonicate) used in these assays: axenic strains of these protozoa need serum rich media for exponential growth. ${ }^{8}$ It is tempting to assume that the United Kingdom sera react predominantly to the bovine serum protein component of the antigen, thus facilitating its removal with the appropriate diluent. The Indian sera, however, seem to react to protozoan components and hence react specifically to Giardia antigen as shown by the confirmatory ELISA. It would be reasonable to state that crude antigens are not ideal for such ELISAs and perhaps purified protein and membrane pellet antigens ${ }^{910}$ should be considered even for routine use.

The reasons for ethnic variations in serological responses to certain animal proteins is also unclear. Some workers have observed that certain groups of people from the Western hemisphere may produce such responses because of increased uptake of dietary antigens or due to an enhanced immunological response to these antigens. ${ }^{7}$ It is as yet not known why some people produce this response while others do not; or why in our study several children with colitis or Crohn's disease reacted the way they did.

This study was supported in part by the Wellcome Trust. We are grateful to Professor J Walker-Smith and Dr M J Farthing of the Departments of Paediatric Gastroenterology and Gastroenterology, St Bartholomew's Hospital, London, respectively, for making available to us sera from patients with inflammatory bowel disease and reagents for the ELISA. We are indebted to Professor P S Shetty, Nutrition Research Centre, St John's Professor P S Shetty, Nutrition Research Centre, St John's

Mary Queenie and Ms Selvi for preparation of the manuscript.

1 Healy GR, Kraft SC. The indirect haemagglutination test for amobiasis in patients with inflammatory bowel disease. Am J Dig Dis 1972;17:97-9.

2 Moody AH, Ridley DS, Tomkins AM, Wright SG. The specificity of serum antibodies to Giardia lamblia and to enterobacteria in gastrointestinal disease. Trans $R$ So Trop Med Hyg 1982;76:630-2.

3 Yang J, Kennedy MT. Evaluation of the ELISA for the serodiagnosis of amoebiasis. J Clin Microbiol 1979; 10:778-81.

4 Shetty N, Prabhu T. IgG ELISA for invasive amoebiasis in endemic areas. The National Medical Journal of India 1989;2:119-21.

5 Goka AKJ, Rolston DDK, Mathan VI, Farthing MIG. Diagnosis of giardiasis by specific IgM antibody ELISA. Diagnosis of giardiasis

6 Goka AKJ, Farthing MJG. The use of 3,3',5,5'-tetramethyl benzidine as a peroxidase substrate in microplate enzyme linked immunosorbent assay. J Immunoassay 1987;8: $29-41$

7 Lerner A, Rossi T, Park B, Albini B, Lebenthal E. Serum antibodies to cow's milk proteins in paediatric inflammatory bowel disease: Crohn's disease versus ulcerative colitis. Acta Paediatr Scand 1989;78:384-9.

8 Diamond LS, Harlow DR, Cunnick CC. A new medium fo the axenic cultivation of $\mathrm{E}$ histolytica and other Entamoebae. Trans $R$ Soc Trop Med Hyg 1978;2:431-3.

9 Grundy MS. Antigen fraction from Entamoeba histolytica strain HK9 for use in ELISA. Arch Invest Med 1982;3(Suppl 13):249-51.

10 Rosoff JD, Stibbs $\mathrm{HH}$. Isolation and identification of a Giardia lamblia-specific stool antigen (GSA 65) useful in coprodiagnosis of giardiasis. J Clin Microbiol 1986;23: 905-7. 